\title{
Adaptaciones teatrales en el cine de Pedro Almodóvar: Cocteau, Williams y Lorca.
}

\section{Theatre Adaptations in the cinema by Pedro Almodóvar: Cocteau, Williams and Lorca.}

\author{
De la Torre Espinosa, M. ${ }^{1}$
}

Recibido: 26-11-2017 - Aceptado: 14-06-2018

DOI: https://doi.org/10.26441/RC17.2-2018-A4

RESUMEN: El cine de Pedro Almodóvar ha sido considerado reiteradamente como teatral. El motivo, en muchas ocasiones, ha sido la recurrencia a intertextos teatrales. El objetivo de este artículo es analizar el modus operandi del director español a la hora de adaptar obras teatrales en su filmografía. Para ello se analiza la puesta en escena fílmica de las obras $L a$ voz humana de Jean Cocteau, Un tranvía llamado deseo de Tennessee Williams y Bodas de sangre y Yerma de Federico García Lorca en los filmes La ley del deseo, Mujeres al borde de un ataque de nervios y Todo sobre mi madre. Siguiendo las clasificaciones de Anxo Abuín y de José Antonio Pérez Bowie, podemos concluir que el artificio detectable en gran parte de su cine es derivado a una concepción de theatrum mundi, donde todo queda imbuido de una performatividad evidente.

Palabras clave: intermedialidad; teatralidad; adaptación cinematográfica; Pedro Almodóvar; cine español.

ABSTRACT: The cinema by Pedro Almodóvar is considered as theatrical. As main reason, the continued use of theatre intertexts. The main goal of this article is study the modus operandi of the Spanish filmmaker in the adaptation of theatre plays in his cinema. We will analyze the mise-en-scene of the plays La Voix Humaine by Jean Cocteau, A Streetcar Named Desire by Tennessee Williams, and Bodas de Sangre and Yerma by Federico García Lorca in the films La ley del deseo, Mujeres al borde de un ataque de nervios and Todo sobre mi madre. According the classifications by Anxo Abuín and José Antonio Pérez Bowie, we conclude that the artifice of this cinema is inserted in a theatrum mundi vision, with an evident performativity.

Keywords: intermediality; theatricality; film adaptation; Pedro Almodóvar; spanish cinema.

1 Mario De la Torre Espinosa es Doctor en Teoría de la Literatura y del Arte y Literatura Comparada por la Universidad de Granada, profesor de la Facultad de Comunicación y Documentación en la misma universidad y profesor interino de Máster en Nuevos Medios Interactivos y Periodismo Multimedia. mariodelatorre@ugr.es, http://orcid.org/0000-0002-0027-8745 


\section{Introducción}

En la filmografía de Almodóvar observamos la presencia del teatro en diversas formas. La más evidente mediante la citación de otras obras, algo que nos permite identificar directamente el intertexto y descubrir así la fuente original, especialmente cuando dichas menciones se realizan en su versión escenificada, enmarcadas además casi siempre dentro de una sala de teatro convencional a la italiana. Pero en otras ocasiones estas alusiones siguen otras estrategias que provocan que esta identificación sea más compleja, dificultando el reconocimiento del producto cultural originario.

En parte importante de la filmografía almodovariana, de la que aquí daremos cuenta de varios títulos, hallamos lo que Pérez Bowie (2010) denominó como "la asunción premeditada de las limitaciones teatrales" -si bien hay que señalar que esta idea del teatro se corresponde con una visión anacrónica del mismo-. Supone el respeto de las tres unidades aristotélicas, aceptando unas férreas limitaciones de espacio y tiempo que condicionarán tanto la historia como la puesta en escena. En Entre tinieblas (Pedro Almodóvar, 1983), aunque no en la totalidad de su metraje, sí se puede observar cómo está presente cierta concentración espacio-temporal. Partiendo del modelo de las películas pop españolas de monjas, el convento se convierte en un microcosmos que acoge las vicisitudes de un peculiar grupo de mujeres reunidas por circunstancias diversas, ya sea por una verdadera vocación religiosa o bien por otros motivos más mundanos. El enclaustramiento de estas religio- sas dentro del edificio se convertirá en el motor de numerosos e hilarantes acontecimientos, dándose lugar incluso a la creación de espectáculos musicales.

La presencia de estas limitaciones teatralizantes puede estar en la base de que esta película fuera llevada al teatro en España en 1992, bajo el título de Entre tinieblas, la función, y en una versión escrita y dirigida por Fermín Cabal (Fig. 1). El relativo éxito de esta adaptación a las tablas promovería la aparición de otros montajes de esta misma obra. Suponía el de Cabal el primer intento de llevar al escenario el universo cinematográfico almodovariano, algo que con posterioridad también sería llevado a cabo en el extranjero, como en los casos de EE. UU., Reino Unido, Austria o Alemania, aunque ahora partiendo de otras películas que albergan distintas formas de teatralidad.

Lo que parece claro es que la potencialidad de la filmografía de Almodóvar para ser llevada a la escena es más que evidente, y así ha sido percibido desde diferentes sistemas culturales. Revisando la producción cinematográfica de los últimos cincuenta años podemos decir, y sin miedo a equivocarnos demasiado, que pocas trayectorias cinematográficas han proporcionado tanto material de partida para su adaptación a los escenarios como el cine de Almodóvar. Su potencialidad intermedial es más que evidente como analizaremos en sus filmes La ley del deseo (1987), Mujeres al borde de un ataque de nervios (1988) y Todo sobre mi madre (1999), tres obras que muestran diferentes grados $y$ formas de teatralidad. 
Figura 1. Entre tinieblas, la función (1992)

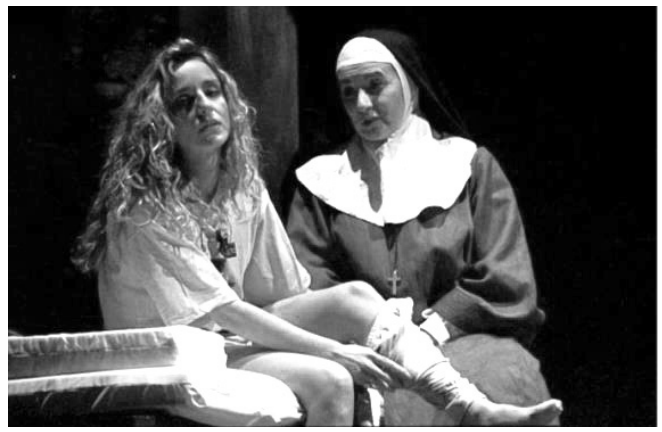

\section{Marco referencial y metodología empleada}

Almodóvar, en el catálogo del ciclo y la exposición que organizaría la Cinémathèque Française en su honor, explicitaba que sus obras "sont pleins de films. Il y a toujours un téléviseur qui en passe un ou un cinéma où se rendent mes personnages" (2006, p. 18). Además, manifestaba que la presencia de estas películas en su filmografía no era nunca azarosa, ya que todos los fragmentos habían sido meticulosamente seleccionados, jugando asimismo un papel activo como parte del guion. De esta intencionalidad no cabe duda, y la crítica cinematográfica, muy interesada siempre que se trate de hablar del cine dentro del cine, ha hecho múltiples referencias a este respecto (véase como ejemplo Holguín, 1994, pp. 118-139; Rodríguez, 2004, pp. 95145). Hablamos así de una metatextualidad que añade una indudable complejidad semiótica al análisis de sus películas, especialmente porque establece diferentes niveles narrativos en su discurso.
Si este fenómeno ha sido muy analizado, los estudios sobre la presencia del teatro en las películas Almodóvar, en cambio, han sido bastante más escasos de lo que cabía esperar. A pesar de esto, son meritorios algunos intentos de sistematizar este aspecto de su cinematografía. En este sentido destaca sobremanera la labor de Anxo Abuín (2011, 2012, pp. 155-171), quien, bajo la denominación de almodrama, expande la categoría de lo teatral en su cine hasta configurar un theatrum mundi que abarca la realidad profílmica. Así, para este investigador, esa teatralidad vendrá derivada del regusto por lo artificial y lo (neo)barroco, el exceso, la máscara, la gestualidad, lo ritual, el protagonismo del decorado y los objetos, el kitsch, lo camp/queer, el melodrama, la ironía teatral, la performatividad sexual, el cuerpo, el travestismo, la oposición narración/ mostración, los monólogos, lo esperpéntico, las referencias intertextuales explícitas... (2011, p. 105, 2012, pp. 156-157)

Metodológicamente, tendremos muy en cuenta el tipo de inscripción de lo 
espectacular en los filmes de Almodóvar, recurriendo al análisis de algunos de los fragmentos que, a nuestro parecer, mejor ejemplifican las estrategias de puesta en escena utilizadas en las películas La ley del deseo, Mujeres al borde de un ataque de nervios y Todo sobre mi madre. A la hora de establecer una tipología clasificatoria de la presencia del teatro, o lo teatral, en estos filmes debemos acudir de nuevo a los estudios de Abuín, en concreto a su artículo "El filme de teatro: arte frente a industria, o totus mundus agit histrionem" (2005), donde introduce cuatro posibilidades de funcionamiento. Según el primero de ellos actuaría como desdoblamiento del propio séptimo arte, es decir, un reflejo especular en la trama de su propia dinámica de trabajo, ya sea a través de la mostración de la labor de directores o actores, o bien mediante el registro del desarrollo de rodajes u otro tipo de producciones artísticas similares. La segunda forma de actuación de lo teatral sería como contrapunto del cine, entendido éste en su vertiente más industrial, sometido a fuertes presiones de mercado que imposibilitan un desarrollo completo de todo su potencial artístico al permanecer sujeto a criterios estrictamente comerciales. Se parte aquí de la consideración del teatro como forma de arte prestigiosa y reducto del genio creativo frente a un séptimo arte prostituido. La tercera supondría una reflexión filosófica, con el teatro como marco "para llegar a alcanzar un planteamiento existencial de calado estético y filosófico" (ibíd., p. 140) donde todo en la vida está sujeto a las convenciones de la representación. Y por último, con la presencia del referente teatral en pantalla, se producirá una confluencia metaficcional, resultado de la concurrencia de varios niveles narrativos en pantalla que cuestionarán los propios mecanismos de construcción de la ficción.

Bien es cierto que esta división fue establecida para los "filmes de teatro", entendidos como aquéllos cuyo argumento gira en torno al trabajo de producción de una puesta en escena y/o a los protagonistas involucrados en la misma. Era necesario un análisis más amplio que transcendiera el ámbito temático y se adentrara en lo formal, y en este sentido actuará Pérez Bowie (2010) al superar la noción de "filme de teatro" y matizar las categorías establecidas por Abuín, intentando así abarcar todos los tipos posibles de teatralidad en la pantalla. Para ello establece diez categorías, seis de acuerdo a criterios formales y cuatro referentes al contenido:

1. La inevitable teatralidad del Modo de Representación Primitivo, donde la dependencia del teatro era absoluta en los inicios del cine, dado que aún no se habían desarrollado convenientemente las capacidades expresivas propias del lenguaje cinematográfico.

2. La teatralidad en el periodo silente del Modo de Representación Institucional, donde recursos como la gesticulación teatral, heredera de la pantomima y el melodrama escénicos, intentaba suplir la ausencia de sonido.

3. La teatralidad «sin complejos» del cine de los años 40-50, donde, a pesar de una mayor psicologización por la 
llegada del cine sonoro, y la consecuente presencia de parlamentos largos, así como por una planificación y un montaje más sofisticados, es plena la consciencia de lo teatral, obligando al espectador a asumir algunas convenciones propias de la escena, como ocurre con los decorados artificiosos de las películas de Douglas Sirk.

4. La reteatralización en algunos filmes contemporáneos: hacia una estética de la resistencia, donde la teatralidad es provocada intencionadamente y cuya lógica hay que interpretarla desde una perspectiva posmoderna.

5. Teatralidad y convención genérica, donde lo teatral es derivado de la adscripción de ciertas películas a determinados géneros cinematográficos donde este carácter es inherente, como ocurre en el caso del musical.

6. La asunción premeditada de las limitaciones teatrales, donde películas, que no son adaptaciones de obras teatrales, asumen las tres unidades aristotélicas, concentrando habitualmente su acción en un único espacio y un tiempo muy reducidos.

7. La teatralidad como especularidad simple: la inserción de una representación en la diégesis fílmica, donde la ficción cinematográfica enmarca la teatral, ya sea con una función tematizadora, simbólica, paralelística, constrastiva o de homenaje.

8. La teatralidad como especularidad compleja, donde la puesta en escena de una obra forma parte importante además del núcleo argumental de la película.
9. La teatralidad reflexiva: el metadiscurso paralelo, donde la representación sirve como pretexto para realizar una reflexión a un nivel metadiscursivo.

10. La teatralidad extraescénica, donde el teatro sale de sus espacios tradicionales de representación a través de la performativización de nuevas identidades, o bien mediante la presencia de formas teatrales poco convencionales, como pueden ser el happening o el teatro de calle.

Gracias a estas clasificaciones podremos inferir el tipo de teatralidad presente, y su modo de funcionamiento, en las diferentes escenas de las películas de Almodóvar, para intentar hallar patrones de acción en el uso y adaptación de estos elementos del repertorio. A la hora de abordar estos fragmentos también tendremos en cuenta el concepto de intertextualidad. Si bien compartimos con Pérez Bowie el reconocimiento de la aparición de nuevas "aportaciones superadoras del marco exclusivamente intertextual" (2004, p. 281) para el análisis de las relaciones entre el cine y sus textos-fuente, entre las que se encuentra el análisis polisistémico de Cattrysse (1992), por ejemplo, este concepto nos parece de total operatividad para abordar el análisis de fragmentos fílmicos que ponen de manifiesto la voracidad textual y la asimilación de diversas formas en la práctica cinematográfica de las películas del director español. Seguimos así la senda de la intertextualidad, derivada conceptualmente del dialogismo bajtinano y acuñada terminológicamente por Julia Kristeva, tal como fue recogida -aunque de forma 
más restrictiva- por Genette (1982). Si antes citábamos dos tipologías de lo teatral, este enfoque nos permitirá además observar el funcionamiento entre los textos puestos en acción, analizando si el uso que se hace de ellos se realiza en forma de cita, plagio o alusión.

Los intertextos seleccionados se corresponden con obras que forman parte de la tradición teatral universal, y que además representan diferentes ámbitos culturales, dando buena cuenta de la diversidad de intereses culturales en la filmografía almodovariana. El corpus seleccionado se corresponde con $L a$ voz humana de Jean Cocteau, Un tranvía llamado deseo de Tennessee Williams, y Bodas de sangre y Yerma de Federico García Lorca (esta última a través de una versión realizada por Lluís Pasqual en Haciendo Lorca).

A priori, podemos decir que el empleo que se hace de estos textos, más allá de servir de homenaje, sigue la lógica generalizada de las adaptaciones fílmicas, es decir, "como elemento articulador de la trama y también como estrategia de mise-en abyme" (Pérez Bowie, 2012, p. 432). Si partimos además de la idea de que la originalidad del cine "reside, paradójicamente, en la audacia de su imitación, cita y absorción de otros textos, su hibridación irónica de discursos tradicionalmente opuestos" (Stam, Burgoyne, y Flitterman-Lewis, 1992, p. 235), podremos ver cómo la presencia y el análisis de lo teatral en el cine de Almodóvar es totalmente lícito.

Una vez detectados y revelados los intertextos teatrales, y su forma de inserción en estas películas, intentaremos de- ducir las normas operacionales de este proceso de translación de modelos de un medio a otro, para discernir los mecanismos puestos en funcionamiento durante este proceso de transferencia de forma y significado entre diferentes prácticas discursivas -teatro y cine- dentro de la filmografía de Almodóvar.

Para la descripción formal de estos fragmentos usaremos como referencia tres obras que se muestran como utilísimas herramientas para el análisis textual: Cómo se comenta un texto fílmico (Carmona, 1996), El análisis de los espectáculos: teatro, mimo, danza, cine (Pavis, 1996) y Análisis del film (Aumont y Michel, 1988).

\section{Resultados}

\subsection{La voz humana de Cocteau, dos vi- siones sobre una obra}

La voz humana de Cocteau se ha convertido en un intertexto ampliamente analizado en la filmografía de Almodóvar, especialmente por las diferentes tácticas de adaptación empleadas y por su presencia en dos de sus más exitosas películas. La primera de ellas se corresponde con La ley del deseo (1987), donde se recurre a la inserción de un fragmento de la representación de esta obra protagonizada por Tina Quintero bajo la dirección de su hermano Pablo. Se trata de un caso de teatro enmarcado, a modo de cita, que nos deja entrever además un llamativo plan de puesta en escena.

Recordemos que la pieza de Cocteau es un monólogo breve para una sola actriz, que vive desconsolada un duro trance: el hombre al que ama, y que la 
ha abandonado, se va a casar con otra mujer. En el escenario sólo aparece una cama y un teléfono que tendrá un papel clave en la obra, ya que la protagonista mantendrá durante toda la representación una conversación con su examante por teléfono, diálogo interrumpido por continuos fallos técnicos. Una fuerte dosis de sentimentalismo inunda la propuesta, exigiendo una interpretación desgarrada por parte de la intérprete que, según las didascalias del propio autor, tiene que comportarse como un animal herido cuya sangre debe inundar el escenario.

La puesta en escena creada para esta película refuerza la desesperación presente en la historia, llevándola al límite mediante el empleo del contraste. Se muestra sólo un par de interludios de la obra, uno que podría corresponderse con el inicio de la obra de Cocteau y otro con su final. Al comienzo vemos cómo Tina destroza con un hacha parte del decorado, que reproduce su desordenado dormitorio. Lleva un camisón de seda y tirantes blanco, y grita mientras asesta enrabietada golpes a las paredes. Suena una versión del Ne me quitte pas de Jacques Brel, en la voz de la artista brasileña Maysa Matarazzo, que dota de un gran dramatismo melancólico a la propuesta. En primer término Ada, la hija de Tina, va siendo desplazada sobre una plataforma con ruedas atravesando todo el proscenio, de frente al público y de izquierda a derecha, mientras va cantando en playback este tema musical y realiza algunos gestos de mímica, escasos pero muy expresivos, acompa- ñando la canción (Fig. 2 y 3). El contraste entre la dulzura de la joven -así como su movimiento lento y fluido sobre el escenario-, y la actitud agresiva de la protagonista refuerza el sentimiento de desesperanza que se halla en la base de la obra original.

En cambio, en el segundo fragmento vemos cómo se reproduce el mismo movimiento de la intérprete sobre raíles, pero ahora en un sentido inverso. Tina ahora aparece abatida en el suelo, y Ada llora (Fig. 4 y 5). Las lágrimas de la pequeña son muy significativas. Son consecuencia del encuentro que acaba de tener en los camerinos con su madre (Bibiana Fernández), quien le ha comunicado que se marcha de nuevo. Tanto la pequeña como su padre/ madre -Tina es transexual- han sido reiteradamente abandonadas por ella. De esta manera, la selección de la pieza de Cocteau, así como su ambientación musical en la puesta en escena de la película, provoca la creación de un nuevo nivel narrativo metaficcional al coincidir estos intertextos con la caracterización y las biografías de los personajes.

Se produce así el refuerzo de una teatralidad que trasciende la escena para afectar la vida privada de los personajes que escenifican la obra. Estaríamos hablando de un ejemplo de teatralidad como especularidad compleja (Pérez Bowie, 2010, p. 48), una ficción en segundo grado que actúa, además de espejo, de refuerzo de lo narrado. Y esto no sólo afecta a Tina y a Ada, sino que es extensible a toda la película, en cuanto se muestra 
como una sucesión de dolorosos abandonos: Pablo por Juan, Antonio por Pablo, Tina por su padre y más tarde por la madre de su hija, y Ada por su madre. Una serie de acontecimientos que van marcando el aire de desamparo que inunda todo el filme, secundado además, y de forma eficaz, por la presencia en la banda sonora de diferentes temas musicales -como los boleros o el tema Ne me quitte pas-, subrayando esta sentimentalidad doliente.

La teatralidad en la película también se hace muy significativa a través del modo de mostración del fragmento. La cámara se ubica entre el público, en concreto en el patio de butacas, apoyando la sensación de visionado de un espectáculo teatral al reproducir el punto de vista del espectador en un teatro a la italiana, especialmente por poder ver en plano entero a las actrices, y oírse los gemidos de Tina siguiendo la lógica que marca la distancia de la cámara con el objeto filmado. Esta sensación también es favorecida por el hecho de que toda la escena transcurre en un solo plano, una panorámica de seguimiento del movimiento de Ada sobre el escenario -con un reencuadre final hacia la izquierda para seguir a Tina, que va hacia el teléfono, ubicado en ese lado de la escenografía-. Al haberse optado por esto, en lugar de recurrir a una planificación más compleja y un montaje más elaborado, se incrementa sin lugar a dudas la sensación de teatro filmado: se produce una correspondencia en la ocularización y la auricularización (Gaudreault y Jost, 1990) con la que sería propia del espectador en este tipo de espectáculo.

Figuras 2, 3, 4 y 5. Representación de La voz humana en La ley del deseo (Pedro Almodóvar, 1987)
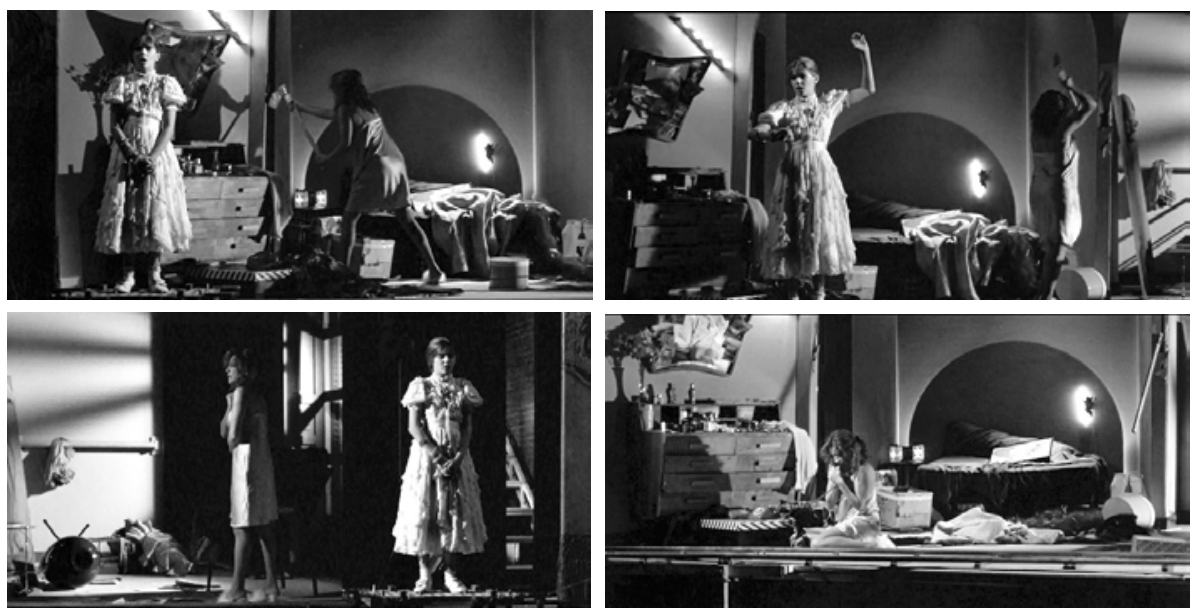
Dado que durante la representación no se declama ni una línea de la obra original, nos parece interesante señalar el modo en el que conocemos la identidad de la pieza escenificada: a través del diálogo, mediante un plano corto del libreto con el que Pablo prepara la función (Fig. 6) y gracias al cartel publicitario del montaje (Fig. 7), un paratexto epitextual que aparece en las paredes de diferentes espacios. Este último elemento, creado por Juan Gatti para el filme, ubica al teléfono como elemento central del diseño, siguiendo la misma lógica que Cocteau impusiera en su obra teatral. Resulta muy curioso observar la reflexión que realiza Barthes sobre la presencia del teléfono en la literatura -y que hacemos extensible a otro tipo de prácticas significantes-. El pensador francés, en su conferencia de 1964 titulada Semántica del objeto, analiza la vinculación de algunos artefactos a la mujer: "¿Puede imaginarse un objeto más funcional que un teléfono? Sin embargo, la apariencia de un teléfono tie- ne siempre un sentido independiente de su función: un teléfono blanco transmite cierta idea de lujo o de femineidad" (Barthes, 1985, p. 248). Nos habla de una doble entidad del objeto, una que remite a su propia funcionalidad y otra que la trasciende con otras significaciones, como sucede aquí, donde el teléfono es contemplado como correlato de la condición femenina al representar el ámbito doméstico donde tradicionalmente se ha recluido a las mujeres. Cocteau, consciente de la importancia que este medio de comunicación interpersonal estaba alcanzando en las primeras décadas del siglo $\mathrm{XX}$ entre ciertos sectores más pudientes de la sociedad, y que se convertía en un artilugio de gran importancia para la comunicación de las amas de casa, lo ubica en el centro de su obra. Además emplea una curiosa paradoja, ya que este aparato creado para la comunicación es usado en cambio para acentuar la soledad y el abandono que sufre la protagonista de La voz humana.

Figuras 6 y 7. Fotograma de La ley del deseo (Pedro Almodóvar, 1987) y cartel de La voz humana presente en la película
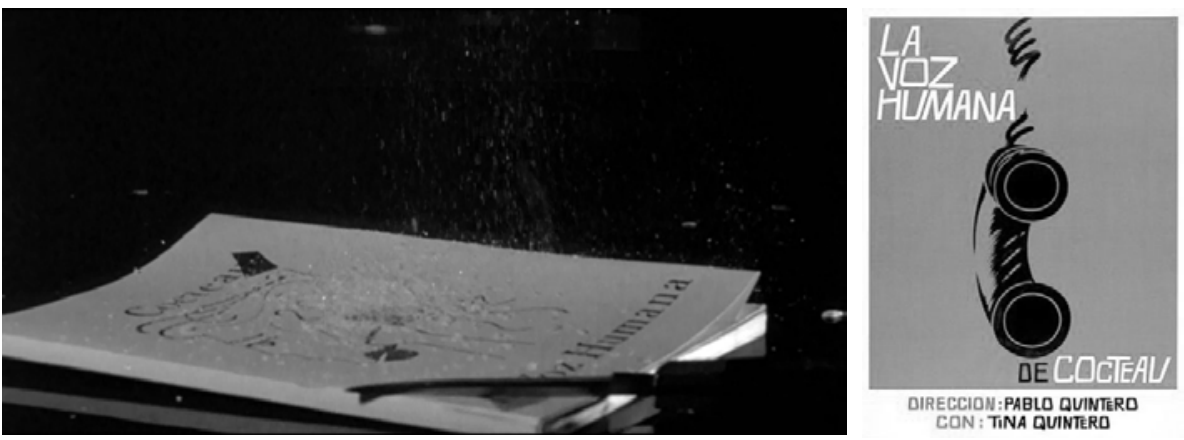
Figuras 8, 9, 10 y 11. La importancia del teléfono en Mujeres al borde de un ataque de nervios (Pedro Almodóvar, 1988)
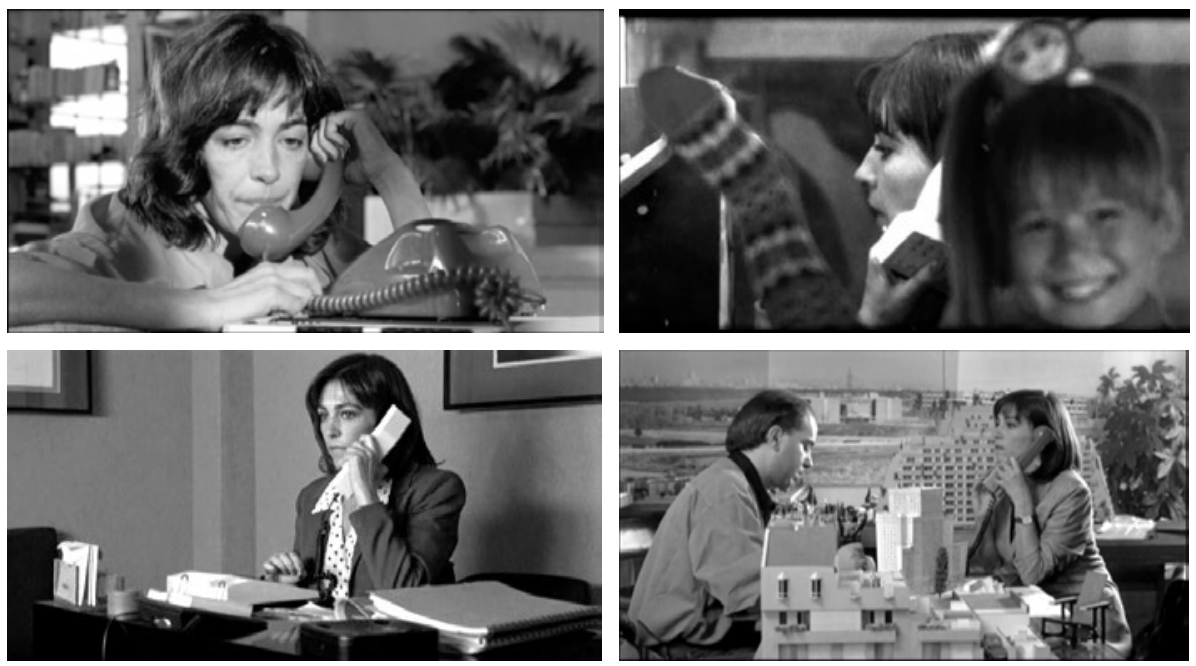

La presencia del teléfono tendrá una importancia capital, también en este sentido paradójico, en el desarrollo de la historia de otra de sus películas más importantes, Mujeres al borde de un ataque de nervios, producción que en principio iba a ser una mera adaptación de la obra de Cocteau. De esta idea inicial quedan numerosos vestigios. Además de la presencia del teléfono, de color rojo al igual que en La ley del deseo y muy en consonancia con la escala cromática dominante en la filmografía del autor, persistirá el retrato de una mujer abandonada, en este caso Pepa. En su primera aparición en pantalla, está boca abajo en la cama, con un pijama de seda fucsia, sin saberse muy bien si duerme o si está muerta -como la protagonista de la obra de Cocteau cuando se levanta el telón-. Sólo reacciona cuando oye en el contestador telefónico la voz de Iván, su examante. Se levanta desesperada y va hacia el teléfono. Su rostro demacrado y su desolación, su actitud ante el aparato, así como que al devolver la llamada sea otra persona la que hable, en concreto la telefonista de la sala de doblaje donde trabaja, hacen que la escena remita inexorablemente a la obra de Cocteau. Y lo más importante, el teléfono se convierte en un elemento central de la trama (Fig. 8 a 11), ya que dará pie a numerosos gags, así como le ayudará a resolver el misterio del motivo de su abandono -Pepa coge el teléfono en el despacho de Paulina y descubre así, al final de la película y atando cabos, que ésta es la nueva amante de Iván-. La protagonista de la película mostrará de esta manera clara una dependencia del artilugio, ya que 
pasará parte importante del metraje hablando por teléfono. Y esto desembocará en otra característica altamente teatralizante, una verbosidad que singulariza tanto a la película como a toda la filmografía de Almodóvar, una preferencia en ocasiones por la narración oral en lugar de la ilustración mediante recursos visuales de los conflictos del argumento.

Figuras 12, 13, 14 y 15. Mujeres al borde de un ataque de nervios (Pedro Almodóvar, 1988)
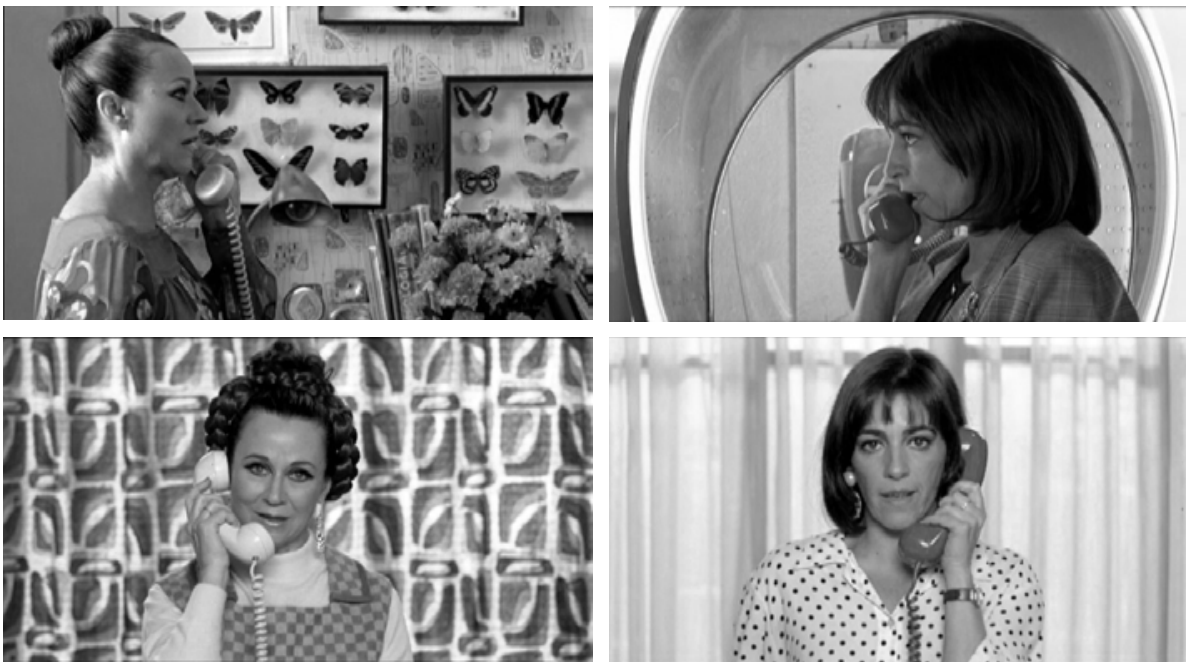

El teléfono, como elemento iconopelícula destacará por el empleo del Technicolor y por el uso de la pantalla partida (split screen) para mostrar las conversaciones. En la película de Almodóvar vemos cómo también se recurre a esos colores intensos, y aunque no se acuda a la división de la pantalla, mediante la disposición de los actores en el plano y el montaje, se enfrenta a los personajes con un resultado similar. Este aspecto es evidente en los duelos telefónicos que mantienen Pepa, la heroína de la historia, con Lucía, la loca antagonista que pretende asesinar a Iván (Fig. 12, 13, 14 y 15). En la primera ocasión en la que hablan entre ellas 
son filmadas de perfil. En la segunda, y la más significativa, están de frente y mirando directamente a cámara. La violencia de la propuesta visual ayuda a incrementar la brusquedad del enfrentamiento entre estas dos mujeres. La teatralidad, por su parte, surge en el momento en el que el espectador es interpelado directamente por la mirada de estas dos actrices, desvaneciéndose el efecto de la cuarta pared propia del cine clásico hollywoodiense. Se rompe así con la verosimilitud al evidenciarse la técnica y el lenguaje cinematográfico, beneficiándose de este modo el tono farsesco que adquiere toda la película.

Este tono disparatado nos recuerda al teatro de vodevil de Feydeau, y a su vez nos remite a la screwball comedy, género al que se podría adscribir esta película. En este tipo de obras, teatrales y cinematográficas, el uso del espacio es fundamental. Si bien en Mujeres al borde de un ataque de nervios no se lleva a cabo la filmación de una puesta en escena de la obra de Cocteau como vimos en el caso de La ley del deseo, son observables una serie de rasgos que incrementan la sensación de teatralidad. El primero de ellos viene derivado del uso de un espacio muy limitado en la planificación cinematográfica -y que al mismo tiempo favorecerá el trabajo con los actores-. El piso de Pepa se convierte en una suerte de escenario con diferentes alturas, donde la entrada y salida de personajes, en un modo teatral, dota de cierto aire vodevilesco a lo Feydeau a la película, un modelo por otra parte reconocido por el director manchego. En este sentido una planificación predominantemente frontal, que muestra en plano entero a los actores en tomas de larga duración, sigue esta línea de mostración de la realidad profílmica de un modo artificioso, como se puede observar en las escenas que transcurren en la entrada del dormitorio de Pepa, cuya puerta viene enmarcada por dos repisas que sostienen jarrones con flores, y donde la geometría en la composición y la mostración del suelo convierte en una suerte de escenario todo el espacio representado (Fig. 16). Si a esto sumamos que Pepa tiene que actuar ante los policías que llegan a su ático para simular y hacerles creer que no ocurre nada, podemos ver cómo nos encontramos ante otra muestra de teatralidad, la que Pérez Bowie denominó "representación como ficción de la cotidianeidad" (2010, pp. 59-60).

Este carácter teatral será reforzado además por el uso de los decorados que simulan las vistas panorámicas del ático de la protagonista (Fig. 17), que no esconden su condición de trompe l'oeil y que provocan una reteatralización intencionada que homenajea a los decorados artificiosos del cine de Hollywood de los años cincuenta. Este uso del decorado sigue así la lógica presente en el cine de Almodóvar, según la cual "settings frequently have much the same function as they have in theatre of a symbolic or expressionistic nature" (Edwards, 2005, p. 95). Se produce así una expansión del mundo de la escena hasta inundar toda la película, una especie de theatrus mundi que difumina las fronteras entre lo cinematográfico y lo teatral, donde las pasiones son fingidas e incluso los sueños pueden hacerse realidad -como en el 
final de la película, cuando se despierta Marisa diciendo que cree haber perdido la virginidad mientras dormía y que es una alusión a El sueño de una noche de verano de William Shakespeare-.

Esta idea de expansión de lo teatral como artificio será ratificada con la inclusión del tema musical que cierra la película, Puro teatro, compuesta por Curet Alonso e interpretada, con su característico histrionismo, por La Lupe:
Igual que en un escenario / finges tu dolor barato. / Tu drama no es necesario / ya conozco ese teatro. / Mintiendo, que bien te queda el papel. / Después de todo parece / que esa es tu forma de ser. / Yo confiaba ciegamente / en la fiebre de tus besos. / Mentiste serenamente / y el telón cayó por eso. / Teatro, lo tuyo es puro teatro, / falsedad bien ensayada, / estudiado simulacro.

Figuras 16 y 17. Representación teatral del espacio en Mujeres al borde de un ataque de nervios (Pedro Almodóvar, 1988)

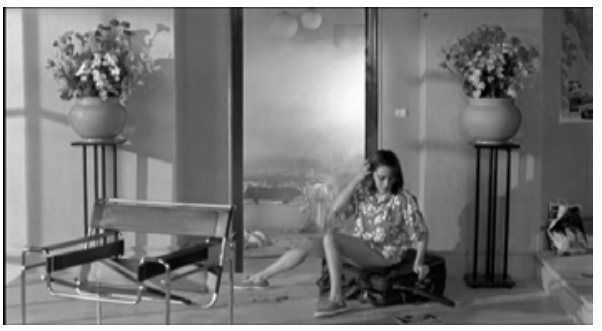

3.2. Un tranvía llamado deseo, entre la puesta en escena y la metaficción

Han sido varios los intentos de adaptar al cine la obra teatral de Tennessee Williams. Entre sus piezas llevadas a la gran pantalla destacan Cat on a Hot Tin Roof (Richard Brooks, 1958), Sweet Bird of Youth (Richard Brooks, 1962), Suddenly, Last Summer (Joseph Leo Mankiewicz, 1959) y The Night of the Iguana (John Huston, 1964), todas ellas bajo el paradigma del modelo del cine clásico hollywoodiense. Pero sin lugar a dudas, una de las adaptaciones más célebre se corresponde con el film Un tranvía llamado deseo (A Streetcar Named Desire), dirigido por Elia Kazan en

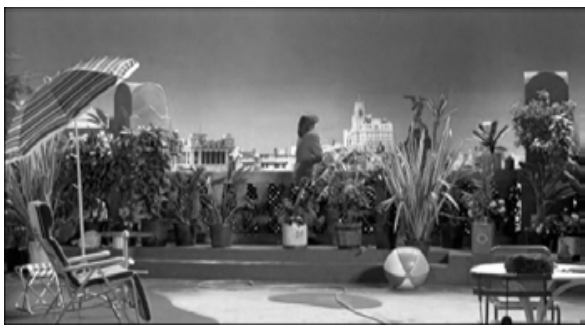

1951. Supondría una traslación a la pantalla muy fiel del universo de Williams, con Vivien Leigh en el papel de Blanche Dubois, que además supondría el descubrimiento de una estrella del celuloide, Marlon Brando.

Esta película se constituirá en todo un referente a la hora de llevar a la escena este mismo texto en Todo sobre mi madre, donde se realiza un trabajo de adaptación con unos objetivos y técnicas muy diferentes, actuando Almodóvar como dramaturgo al "ubicar los materiales textuales y escénicos, extraer las significaciones complejas del texto escogiendo una interpretación particular, y orientar el espectáculo en el sentido 
elegido" (Pavis, 2002, p. 157). Además de los mecanismos metaficcionales (siguiendo la definición de metaficción de Patricia Waugh, 1995) que comentaremos a continuación, Almodóvar opta por representar y filmar sobre el escenario algunos fragmentos de Un tranvía llamado deseo, que tendrán gran importancia a su vez tanto para el desarrollo de los personajes y sus acciones como para la configuración del sentido final del film.

Son varias las formas en las que esta obra de Williams aparece en la película. Manuela, la protagonista, ha perdido a su hijo atropellado cuando corría tras el coche en el que viajaba Huma Rojo, la actriz que está encarnando a Blanche en el teatro y a la que quería pedir un autógrafo. En su juventud, Manuela había protagonizado el papel de Stella Dubois-Kowalski, y volverá a interpretarlo cuando se convierta en la asistenta de Huma y su pareja Nina, la actriz que encarna ese papel en la obra, caiga indispuesta. Además, en diversas escenas de la película se hace presente la representación de la obra, ya sea sobre el escenario u oyéndose sus diálogos entre bambalinas.

Como hemos comentado, la selección y modificación de los fragmentos de esta obra se realizan con el objetivo de actuar como duplicación de lo que ocurre en el guion, integrándose dentro de lo que Pérez Bowie (ibíd.) denomina como especularidad compleja, ya que no sólo se incluyen escenas de la representación teatral, sino que la obra influye en la trama, ya sea comentándola o incluso condicionándola.
Un tranvía llamado deseo, en el texto teatral original, acaba cuando Stella es apaciguada, una vez más, por su marido, mientras que su hermana mayor, Blanche, es internada en un hospital psiquiátrico. En la película de Almodóvar, en cambio, se propone una nueva visión del personaje de Stella para hacerlo coincidir con el propio carácter de Manuela, con el de una mujer valiente que no se achanta y se enfrenta a los infortunios de la vida: tanto Manuela como Stella Dubois abandonan a sus esposos, teniendo ambas mujeres al hijo como resorte para tomar semejante decisión. Es por ello que la Stella de Almodóvar, lejos de ser un personaje pasivo, opone resistencia a su marido. Se implementa una visión novedosa de esta mujer, con la iniciativa y el arrojo necesarios para decidir por sí misma, como se vislumbra en el guion de la película:

Sólo oímos la voz de Kowalski ("Vamos, nena. Ya pasó lo peor") y la de Stella ("No me toques, no vuelvas a tocarme, hijo de puta"). Stella se mueve hacia la derecha del escenario, parece que saliera de la cabeza de Manuela, Kowalski también, como si Manuela los imaginara y proyectara sobre su escenario.

KOWALSKI: iCuidado con lo que dices!... Stella, ven aquí. Stella lleva a su hijo pequeño en los brazos. Vuelve la cabeza, con una mirada triste se despide de la casa. Estrecha al niño contra su pecho en busca de apoyo. Murmura, decidida: -No volveré a esta casa nunca más. iNunca! (Almodóvar, 1999:59-60) 
Es con este personaje con quien Manuela se identifica, con una Stella que, motivada por proteger a su hijo, decide buscar una nueva vida para ambos. De este modo, Manuela se inserta en una larga lista de personajes almodovarianos cuya identidad es definida gracias a la recurrencia de intertextos, produciendo una ficcionalización en segundo grado de los avatares de los protagonistas. Con Huma Rojo nos encontramos con otro caso de este mismo método de construcción de personajes. Si Manuela es una Stella remodelada, ella es una nueva Blanche. Manuela, en el viaje a Barcelona para reencontrarse con el padre de su hijo, acude a una función de Un tranvía llamado deseo, el mismo montaje que vio con su hijo la noche que este murió atropellado. $\mathrm{Al}$ finalizar, va a visitar a Huma a su camerino. La actriz espera a Nina, pero ésta se ha marchado en busca de drogas, y le pide a Manuela que le ayude a encontrar a su amante. En este contexto la diva se adueña de la personalidad de Blanche Dubois con una frase célebre, enunciada además en el primer fragmento de la obra que vemos al comienzo de la película: "Gracias; quien quiera que seas, siempre he confiado en la bondad de los desconocidos". Se produce así, mediante este parlamento, una indiferenciación entre el teatro y la vida real de la estrella de la escena, una confusión de identidades que prolonga el hecho teatral en el filme más allá del escenario.

Como vemos, Almodóvar pone en escena algunos fragmentos de Un tranvía llamado deseo de diferentes formas, difu- minando los límites entre el código cinematográfico y el teatral. Nos parece oportuno convocar aquí la idea de puesta en escena de Ramón Carmona, en cuanto destaca el vínculo que se establece entre ambos medios:

El término puesta en escena viene del teatro y significa montar un espectáculo sobre el escenario. Aplicado al trabajo fílmico, describe la forma y composición de los elementos que aparecen en el encuadre. El desplazamiento metafórico del término teatral hacia el discurso fílmico tiene, sin embargo, cierta lógica. En efecto, el texto del guion, como el texto dramático, es montado espectacularmente para ser captado por la cámara. (1996, p. 127)

En Todo sobre mi madre se representan varias escenas de Un tranvía llamado deseo, en concreto en el Teatro de Bellas Artes de Madrid y en el Teatro Tívoli de Barcelona, para luego filmarlas. Asistimos en ambos casos a una representación en un teatro convencional, donde se intenta respetar la distribución del espacio escenográfico de la obra de Williams. Éste concebía en primer término el apartamento de los Kowalski, dividido en dos habitaciones por una pared inexistente, una puerta y un arco. En la habitación de la izquierda un par de escalones precedían la puerta del baño, y a su lado las cortinas de un armario. La pared derecha del apartamento comunica con un porche sin techo, y a su derecha una escalera de caracol lleva al piso de arriba, en el que viven Eunice y Steve. A la derecha de la escalera y del porche un 
pasillo sube hasta el nivel de la calle, atravesando el escenario detrás de las dos habitaciones de los Kowalski, y que puede verse cuando está iluminado porque las paredes posteriores del apartamento son de gasa donde están aplicados los contornos de las ventanas. Más allá del telón, que cae inmediatamente detrás de la calle (y que también es de gasa), puede verse un telón de fondo que representa las vías del elevado, que pasa cerca (Williams, 1962, pp. 9-10). En Todo sobre mi madre, en cambio, se huye de este realismo buscado por Williams y se opta por una depuración formal, donde el universo visual pregnante de Bob Wilson inspira la escenografía y la iluminación, demostrando el conocimiento de
Almodóvar de las últimas tendencias escénicas tal y como se puede comprobar en el guion:

La acción transcurre en el espacio que representa la habitación de Blanche. Una cortina la separa del comedor. No hay muebles. También el cuarto de baño está separado de la habitación por una cortina. La casa de los Dubois (incluso en su versión más abstracta) respira precariedad. El decorado puede recordar la desnudez esencial de Bob Wilson, pero la interpretación es de un naturalismo hardcore. En lo que se supone es el comedor, bajo una bombilla desnuda, Kowalski juega al póker con un grupo de sudorosos amigos. (Almodóvar, 1999, p. 26)

Figura 18. Representación de Un tranvía llamado deseo en Todo sobre mi madre (Pedro Almodóvar, 1999)

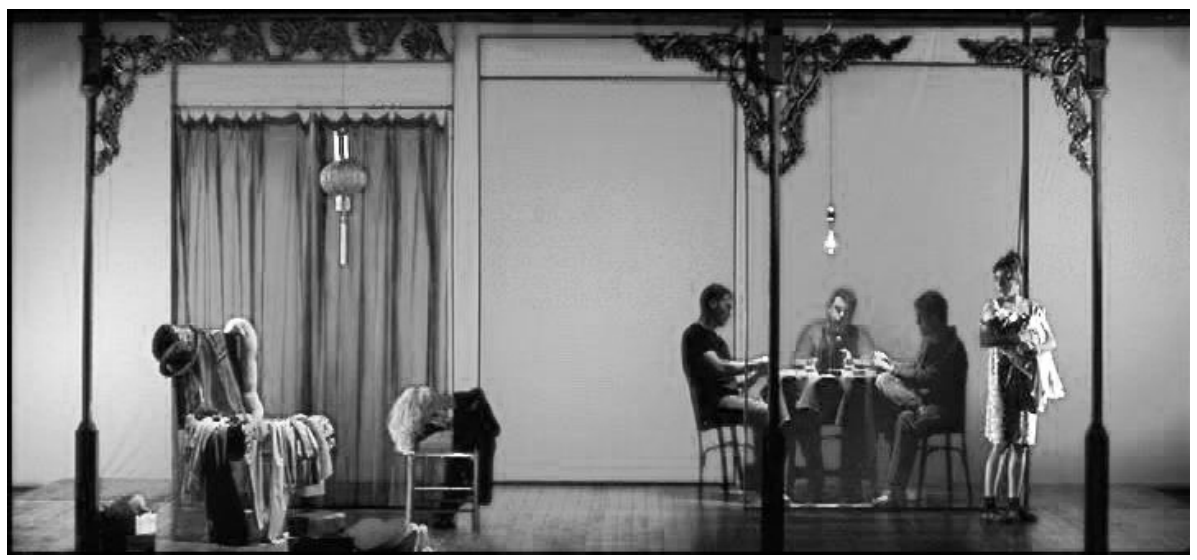

La película respeta el espacio del departamento de los Kowalski, pero elimina tanto la calle como el porche y la escalera, que en la obra original tienen una función escénica muy importante. Podríamos colegir que esta decisión es motivada por el hecho de que en las escenas seleccionadas no se da la 
presencia de estos elementos del decorado. Eso sí, se enmarca el escenario con una marquesina de tres columnas que recuerdan a los porches de la arquitectura popular de Nueva Orleans. Las gasas, por su parte, también están presentes, una separando la habitación de Blanche del comedor y otra más tupida en forma de cortina separando otro espacio. Todo el decorado está imbuido de una gran humildad, como lo sugiere la presencia de una bombilla desnuda bajo la que los hombres juegan a las cartas (Fig. 18).

El vestuario y el maquillaje, por su parte, buscan un efecto de estilización que, sin ser del todo realista, remita a una tipología de personaje concreto. Es un vestuario contemporáneo -con la misma intención que tenía Williams-, sin buscar distanciamientos ni en el lugar ni en el tiempo, intentando acercar así la vida de los personajes de la obra teatral a la de los personajes de la película que los interpretan, es decir, los actores de teatro. En la escena en la que se llevan a Blanche al psiquiátrico, el vestuario de la enfermera denota su profesión: un traje blanco corto, con cofia y medias blancas. El vestuario del doctor es el propio de un hombre adusto y serio, con un traje de chaqueta oscuro que marca el carácter trágico que su presencia tendrá sobre la historia. En cambio, el vestuario de Blanche es muy llamativo. Lleva una bata muy elegante y un gorro hecho con una media. Queda claro que su ropa es demasiado ostentosa para su condición económica, especialmente por su color vivo, con motivos damasquinados de un dorado brillante que contrasta sobre el fondo -un diaporama de azul intenso donde se puede ver la influencia de Bob Wilson, como ya comentamos-, y con las humildes vestimentas de Stella y Eunice, que sí visten acordes a su condición social. Blanche, además, usa pelucas, marcando ese carácter de artificio que tiene su personaje, capaz de inventarse su vida o rehacerla a su antojo.

Sobre la planificación cinematográfica, observamos cómo el "modo de realización de la imagen" (Carmona, 1996, p. 94) es mucho más sofisticado que en La ley del deseo, otra de las películas de Almodóvar donde hallamos ejemplos de teatro enmarcado como cita dentro de la diégesis fílmica como ya analizamos. A pesar de que se repite la presencia de planos que filman casi toda la embocadura del teatro, pudiendo ver a los actores en plano entero y con la cámara ubicada en el patio de butacas -lo que se correspondería con un punto de vista más próximo al teatral-, percibimos también cierta preocupación por explotar mediante el cine todo el potencial cinematográfico de estos fragmentos teatrales al variar la escala de los planos, conscientes de su "importante papel a la hora de indicar el cambio de régimen ficcional y de variar la distancia emocional del espectador en relación con la acción" (Pavis, 2000, p. 122). En este sentido debemos interpretar también la alternancia del punto de vista, como en las secuencias 74 y 75 , donde se asimila con el de Manuela, quien contempla entre bambalinas el transcurrir de la función mientras repite con amargura el texto de Stella que 
aún recuerda de cuando lo representó en su juventud haciendo teatro aficionado. Desde su punto de vista descubrimos todo el dispositivo teatral, quedando toda la tramoya a la vista, aunque enseguida la cámara vuelve a adoptar un posicionamiento frontal a la escena. En otras secuencias, en cambio, la cámara comienza mostrando una total frontalidad, pero se van introduciendo movimientos que evitan un excesivo estatismo en la puesta en escena y disminuye así la sensación de teatro filmado.

Aun así, la teatralidad está presente en el hecho de que nos hallamos ante un filme de teatro en el modo enunciado por Anxo Abuín. La vida en los cameri- nos, los pasillos de los teatros, el trabajo con el vestuario, la peluquería o el maquillaje... son sólo algunos de los aspectos de la escena que quedan ocultos al espectador habitualmente y que aquí son revelados. El hecho de que Manuela trabaje como asistente de Huma, y que más tarde la sustituya Agrado, permite el desarrollo de diferentes subtramas dentro de estos espacios teatrales. Los espejos presentes en los camerinos (Fig. 19), y mostrados frecuentemente, se convierten así en metáfora de la función especular del teatro en la película, reflejando rasgos de la propia vida de las protagonistas, mujeres que tienen que interpretar -dentro y fuera de la escenapara sobrevivir.

Figuras 19 y 20. Todo sobre mi madre (Pedro Almodóvar, 1999)
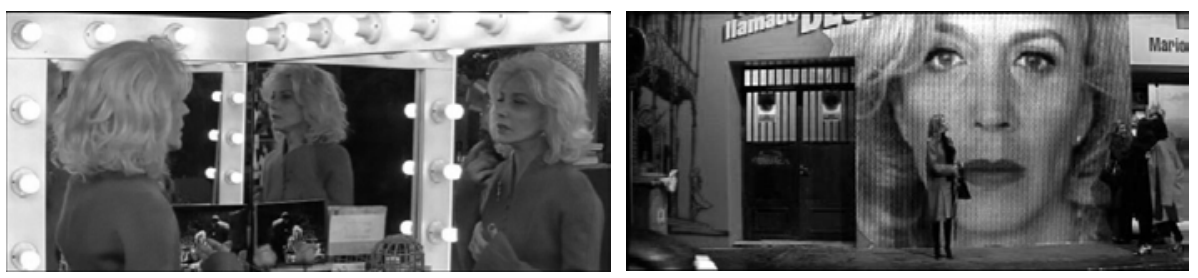

Junto a esto, paratextos como los de los carteles de la obra (Fig. 20), fotografías de otras representaciones teatrales de Huma Rojo -o mejor dicho, de la actriz que la interpreta, Marisa Paredes-, así como la visualización del público que asiste a la representación, dotan de un grado extra de teatralidad a la película. No es casualidad que la película acabe con la caída del telón teatral y con la sobreimpresión de un rótulo con una peculiar y aclaradora dedicatoria: "A
Bette Davis, Gena Rowlands, Romy Schneider... A todas las actrices que han hecho de actrices, a todas las mujeres que actúan, a los hombres que actúan y se convierten en mujeres, a todas las personas que quieren ser madres. A mi madre". Se produce así, con esta dedicatoria, una expansión del hecho teatral más allá de las tablas, donde el concepto de representación alcanza no sólo el medio cinematográfico o teatral, sino que afecta además a categorías como la 
de género, al dedicársela también a los hombres que se convierten en mujeres. Una declaración de principios explícita que sirve para apoyar todo lo percibido durante el visionado: un homenaje a las madres y también al cine, pero al teatralizado.

\subsection{Bodas de sangre y Yerma, de García Lorca}

El último intertexto teatral que vamos a analizar se encuentra también en Todo sobre mi madre, en concreto en la parte final de la película. Se corresponde con un fragmento de Haciendo Lorca, obra de Lluís Pasqual estrenada originariamente el 18 de abril de 1996 en el Teatro Lope de Vega de Sevilla, protagonizada por Alfredo Alcón y Nuria Espert. Escrita a partir de los textos del escritor granadino, se transformaría durante los ensayos, en palabras de María Delgado, en una meditación sobre la tragedia que "pondría el acento en la discontinuidad narrativa y en el conflicto de significados simbólicos" (2001, p. 402).

Huma Rojo recita durante un ensayo un texto de la obra, donde se mezcla Yerma con Bodas de sangre. Lleva su pelo recogido tersamente, una falda estampada, camisa blanca y un mantoncillo rojo, y declama plena de angustia:

Hay quienes piensan que los hijos son cosa de un día. / Pero se tarda mucho, mucho, por eso es tan terrible ver la sangre de un hijo derramada por el suelo. / Una fuente que corre durante un minuto y a nosotras nos ha costado años. / Cuando yo descubrí a mi hijo estaba tumbado en mitad de la calle. / Me mojé las manos de sangre y me las lamí con la lengua, / porque era mía. / Los animales los lamen, ¿verdad? / A mí no me da asco de mi hijo. / Tú no sabes lo que es eso. / En una custodia de cristal y topacio /tendría yo la tierra empapada por su sangre.

Con este parlamento sobre la sangre, usándola en un sentido metaficcional al vincularla al VIH que afecta a Rosa y a Lola (Navarro Daniels, 2002), y la maternidad asistimos al ensayo de la nueva obra que está preparando la diva de la escena. De esta forma conocemos más información acerca de la trayectoria artística de la actriz, otorgando una mayor consistencia a la construcción de su personaje. Pero lo que nos resulta más interesante es que en este momento se recurre a la figura del director de escena, que es filmado no sólo como observador del ensayo, sino también ejerciendo su trabajo mientras observa e imparte directrices. La secuencia arranca con un plano medio de Lluís Pasqual que fuma sentado mientras vigila atento la interpretación de Huma. La cámara inicia un travelling de retroceso y semicircular donde vamos descubriendo a Huma de perfil (Fig. 21 a 24). Al finalizar el movimiento de 270 grados, vemos que el patio de butacas está casi vacío, con sólo dos trabajadoras de la compañía en la sala. En el siguiente plano descubrimos, de frente y en plano entero, a Huma arrodillándose para concluir su monólogo, retornándose así a una planificación teatralizante cómo ya habíamos notado en otros ejemplos anteriores. 
Como hemos dicho, lo que sí supone una gran novedad es la inclusión del proceso de ensayo y, sobre todo, en la importancia que se le da a Pasqual, figura capital del teatro contemporáneo español, al mostrarlo en acción dirigiendo a Huma. El valor otorgado a este trabajo de dramaturgia escénica nos parece esencial. En el siguiente plano, y tras una breve elipsis temporal, Huma trabaja junto a Pasqual, quien, detrás de ella, le indica cómo debe realizar la acción. Hay un acompañamiento cercano, incluso con contacto físico, que se aleja de la visión dada por algunos otros filmes de la figura del director de escena como un tirano despótico con sus actores. Se percibe, en cambio, decisión y mimo en las instrucciones dadas a la actriz, dando una visión altamente positiva de este trabajo de creación escénica.

A través de este fragmento, que pone de relevancia lo maternal de un modo muy terrenal, asistimos a un interesante juego especular complejo, donde la metaficción irrumpe al enmarcarse un nivel narrativo en otro que actúa de comentario de la propia película. La pérdida del hijo de Manuela encuentra así una importante resonancia en esta secuencia, que hace de lo materno una performance abierta al público, de tal manera que dicho final invita a todo/as lo/as espectadoras a buscar una autoidentidad aproximante en lo maternal $y$, al mismo tiempo, a identificarse con la posición no-hegemónica de otros sujetos en relación a lo maternal (Gabilondo, 2005, p. 303).

Esta visión es compartida, entre otros, por Lourdes Estrada, quien hace referencia a este fragmento como un ejemplo de espectacularidad narrativa (Edwards, 2008, p. 293), interesándose en el doble rol de personaje/actriz de Huma Rojo, y generando "un espacio donde 'la potencia de lo falso' se muestra a través del devenir de los personajes en otros" (2014, p. 537).

Figuras 21, 22, 23 y 24. Ensayo de Haciendo Lorca en Todo sobre mi madre (Pedro Almodóvar, 1999)
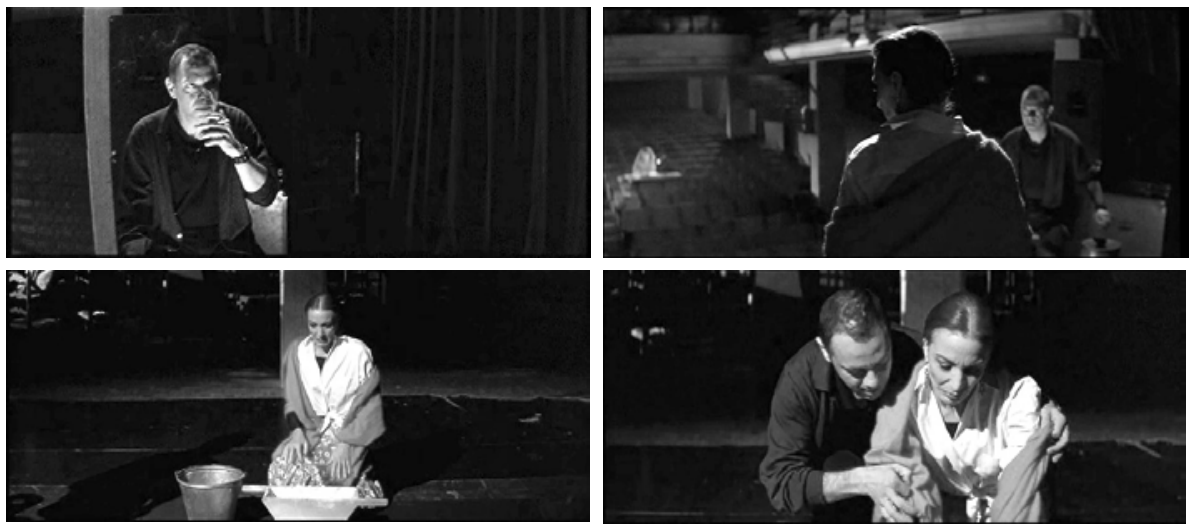


\section{Conclusiones}

Tras revisar estas escenas podemos advertir cómo en las adaptaciones efectuadas se ha producido una asimilación del código teatral al código cinematográfico aunque sin borrar las costuras que delimitan un medio del otro, es decir, evidenciando la intermedialidad. Esto es constatable en la presentación de los intertextos a modo de cita, donde el hipotexto es evidente, rehuyendo así de un discurso naturalista o naturalizante (el modo propio del modelo hollywoodiense) para desembocar en un refuerzo de la ficción.

También es posible observar en la filmografía de Almodóvar una evolución en los modos de inserción de la teatralidad en su cine, que va de la cita explícita (La voz humana en La ley del deseo, por ejemplo) al empleo de estrategias metaficcionales que conllevan una complejidad mayor al indiferenciar los planos narrativos (la metadiscursividad a través de Un tranvía llamado deseo en Todo sobre mi madre). La estilización de su cine se hace patente también en el tratamiento de lo teatral, donde la asunción plena de los presupuestos del melodrama clásico le hace evolucionar hacia una teatralidad más autoconsciente, de igual manera a lo acontecido en el desarrollo de la filmografía de Rainer Werner Fassbinder (Chappuzeau, 2005), tal y como reconoce el propio director español (en Strauss, 2001, p. 127).

La puesta en escena juega en un terreno liminal, en cuanto sin dejar de usar la potencialidad de la gramática audiovisual, no renuncia a la fuerza de ciertos elementos del teatro. Esto se puede advertir en la importancia otorgada al actor, con interpretaciones que se constituyen en el centro de las propuestas. Y también en la mostración del espectador desde sus butacas en el cine, reflejando el estatuto espectatorial del público en un teatro a la italiana, al fin y al cabo el modelo de la sala de cine convencional. Estos filmes, al romper con la invisibilidad enunciativa del modo clásico mediante la mostración del artificio cinematográfico (al develar identidades construidas o espacios recreados), instaura al espectador en un nuevo marco de recepción donde, al igual que el público teatral, debe proceder a una especie de denegación teatral, fenómeno según el cual se asume un pacto de ficción sabiendo que lo mostrado en el escenario no tiene continuidad fuera de la sala. El espacio cinematográfico adquiere así un nuevo significado metafórico (UriosAparisi, 2010), en cuanto todo forma parte del fenómeno espectatorial cinematográfico-teatral.

No sólo asistimos a ejemplos claros de intermedialidad a través de estos intertextos, sino que además estos tienen una importancia fundamental en la diégesis fílmica en cuanto insertan una teatralidad muy compleja. A partir de las tipologías señaladas en el análisis, se puede deducir que estamos ante ejemplos de teatralidad reflexiva (Bowie, 2010, p. 56-57), en cuanto la presencia de la vida teatral en las tramas, y la forma de mostración del mundo escénico, imbuye de una gran metadiscursividad al relato, añadiendo artificiosidad al discurso fílmico y contribuyendo de 
forma decisiva a reforzar la teatralidad de su obra. La indiferenciación entre la vida real de los personajes en la diégesis y la que representan en las obras contribuyen así a que se produzca una confusión que, lejos de minar la expresividad de la propuesta, resemantiza lo visualizado añadiendo un nuevo sentido: todo es una performativización de la vida expuesta ante los ojos del espectador.

Concluyendo, y siguiendo la terminología de Pérez Bowie (2010), vemos cómo estos filmes forman parte de una estética de resistencia frente a la representación del cine clásico y su in- visibilidad enunciativa, donde la teatralidad no consiste solo en la inserción de las representaciones en la diégesis fílmica con funciones tematizadoras, sino que sirven para elaborar un metadiscurso sobre la situación de unos personajes que recurren a la performativización de sus identidades como estrategia vital. Sin lugar a dudas, todo, una vez más, ejemplo de la producción cinematográfica de corte posmoderno de Pedro Almodóvar, en cuanto sus películas configuran una visión de la realidad como theatrum mundi.

\section{Bibliografía}

Abuín González, A. (2005). El filme de teatro: arte frente a industria, o totus mundus agit histrionem. Anthropos, (208), 138-151.

Abuín González, A. (2011). Almodramas, o lo tuyo es puro teatro: el teatro en el cine de Pedro Almodóvar. Boletín Hispánico Helvético, (17-18), 105-125.

Abuín González, A. (2012). El teatro en el cine. Madrid: Cátedra.

Almodóvar, P. (1999). Todo sobre mi madre: guion original. Madrid: Círculo de Lectores.

Abuín González, A. (2006). Carte blanche à Pedro Almodóvar: les films. En La Cinémathèque française. Programme mars-avril 2006 (pp. 17-22). Paris: Cinèmatheque française.

Aumont, J. y Marie, M. (1988). Análisis del film. Barcelona: Paidós, 2009.

Barthes, R. (1985). La aventura semiológica. Barcelona: Paidós, 1993.

Carmona, R. (1996). Cómo se comenta un texto fílmico. Madrid: Cátedra.

Cattrysse, P. (1992). Pour une théorie de l'adaptation filmique: le film noir américain. Berne, Berlin. Francfort-S. Main, New York, Paris, Vienne: Lang.

Chappuzeau, B. (2005). Transgression und Trauma bei Pedro Almodóvar und Rainer Werner Fassbinder. Tübingen: Stauffenberg.

Delgado, M. (2001). Los Lorcas desconocidos de Lluís Pasqual. Teatro: revista de estudios teatrales, (13/14), 387-406.

Edwards, G. (2005). Almodóvar and the Theatre. Anales de la literatura española contemporánea, $30(1), 77-96$.

Edwards, G. (2008). From screen to stage: Almodóvar's All about My Mother. New Review of Film and Television Studies, 6(3): 285-301.

Estrada, L. (2014). 'La potencia de lo falso' en Todo sobre mi madre (1999) de Pedro Almodóvar. Hispanic Research Jorunal, 15(6), 530-546.

Gabilondo, J. (2005). Melodrama atlántico y migrancia materna. Apuntes sobre Todo sobre mi 
madre. En F. A. Zurian y C. Vázquez Varela (Eds.), Almodóvar: El cine como pasión. Actas del Congreso Internacional Pedro Almodóvar (pp. 287-306). Cuenca: Universidad de Castilla-La Mancha.

Gaudreault, A. \& Jost, F. (1990). El relato cinematográfico: cine y narratología. Barcelona: Paidós, 2001.

Genette, G. (1982). Palimpsestos: la literatura en segundo grado. Madrid: Taurus, 1989.

Holguín, A. (1994). Pedro Almodóvar. Madrid: Cátedra, 2006.

Navarro Daniels, V. (2002). Tejiendo nuevas identidades: la red metaficcional e intertextual en Todo sobre mi madre de Pedro Almodóvar. Ciberletras, (7). Recuperado de: http://www. lehman.cuny.edu/ciberletras/v07/navarrodaniels.html

Pavis, P. (1996). El análisis de los espectáculos: teatro, mimo, danza, cine. Barcelona: Paidós, 2001. Pavis, P. (2002). Diccionario de teatro: dramaturgia, estética, semiología. Barcelona: Paidós.

Pérez Bowie, J.A. (2004). La adaptación cinematográfica a la luz de algunas aportaciones teóricas recientes. Signa, (13), 277-300.

Pérez Bowie, J.A. (2010). La teatralidad en la pantalla. Un ensayo de tipología. Signa, (19), 35-62.

Pérez Bowie, J.A. (2012). Literatura y cine: perspectivas de investigación comparatista. En P. Aullón de Haro (Ed.), Metodologías comparatistas y literatura comparada (pp. 427-440). Madrid: Dikynson.

Rodríguez, J. (2004). Almodóvar y el melodrama de Hollywood: historia de una pasión. Valladolid: Maxtor.

Stam, R., Burgoyne, R y Flitterman-Lewis, S. (1992). Nuevos conceptos de la teoría del cine. Barcelona: Paidós, 1999.

Strauss, F. (2001). Conversaciones con Almodóvar. Madrid: Akal.

Urios-Aparisi, E. (2010). Puro teatro: metáfora y espacio en el cine de Pedro Almodóvar. Madrid: Ediciones Libertarias.

Waugh, P. (1995). What is metafiction and why are they saying such awful things about it? London, New York: Longman.

Williams, T. (1962). Teatro. Buenos Aires: Losada.

\section{Filmografía}

Almodóvar, A., Almodóvar, P., Llorens, A. (productores), y Almodóvar, P. (director). (1988). Mujeres al borde de un ataque de nervios [Cinta cinematográfica]. España: Laurenfilm, El Deseo.

Almodóvar, A., Berri, C., Ruben, M. (productores), y Almodóvar, P. (director). (1999). Todo sobre mi madre [Cinta cinematográfica]. España, Francia: El Deseo, Renn Productions, France 2 Cinéma.

Almodóvar, A., Pérez Campos, M.A. (productores), y Almodóvar, P. (director). (1987). La ley del deseo [Cinta cinematográfica]. España: El Deseo, Laurenfilm.

Berman, P.S., Hereford, K. (productores), y Brooks, R. (director). (1962). Sweet bird of Youth [Cinta cinematográfica]. EE. UU.: Roxbury Productions, Metro-Goldwyn-Mayer. 
Calvo, L. (productor), y Almodóvar, P. (director). (1983). Entre tinieblas [cinta cinematográfica]. España: Tesauro S.A.

Feldman, C. (productor), y Kazan, E. (director). (1951). A Streetcar Named Desire [Cinta cinematográfica]. EE. UU.: Charles K. Feldman Group, Warner Bros.

Hunter, R., Melcher, M., Muhl, E. (productores), y Gordon, M. (director). (1959). Pillow Talk [Cinta cinematográfica]. EE. UU.: Arwin Productions, Universal Pictures.

Spiegel, S. (productor), y Mankiewicz, J.L. (director). (1959). Suddenly, Last Summer [Cinta cinematográfica]. EE. UU.: Columbia Pictures, Horizon Pictures.

Stark, R., Whitelaw, S. (productores), y Huston, J. (director). The Night of the Iguana [Cinta cinematográfica]. EE. UU.: Metro-Goldwyn-Mayer.

Weingarten, L. (productor), y Brooks, R. (director). (1958). Cat on a Hot Tin Roof [Cinta cinematográfica]. EE. UU.: Avon Productions, Metro-Goldwyn-Mayer. 